\title{
Investment Trust Performance Analysis Report Based on JPMorgan, Witan and Monks
}

\author{
Wanchao Liu \\ Newcastle Business School, Newcastle University, Newcastle upon Tyne, UK \\ Email:875640849@qq.com
}

How to cite this paper: Liu, W. C. (2020). Investment Trust Performance Analysis Report Based on JPMorgan, Witan and Monks. American Journal of Industrial and Business Management, 10, 1482-1487. https://doi.org/10.4236/ajibm.2020.108097

Received: May 20, 2020

Accepted: August 28, 2020

Published: August 31, 2020

Copyright $\odot 2020$ by author(s) and Scientific Research Publishing Inc. This work is licensed under the Creative Commons Attribution International License (CC BY 4.0).

http://creativecommons.org/licenses/by/4.0/

\begin{abstract}
As an investor, it is critical to review and understand historical performance of each invested trust before making decisions. It reflects whether this invested trust can bring excepted return for investor. Hence, to offer this wealthy investor advice, this report will introduce investment trusts and analyze the index of three stocks over the past five years, including JPMorgan American IT., Witan Inv. Trust and Monks Inv. Trust, to forecast the future performance and generate investment recommendation based on Sharpe, Treynor and Information ratios. Firstly, investment trusts and performance measures will be introduced. Secondly, it will calculate, analyze and compare returns and three different ratios. Then, investment risks, limitations and recommendation will be concluded.
\end{abstract}

\section{Keywords}

Sharpe Ratio, Treynor Ratio, Information Ratio, Risk

\section{Explanation}

\subsection{Explanation of Investment Trusts}

Within the last decades, a wide variety of factors, including low interest rates and high risk on individual investment, investment trust has seen a great development. It is a type of public listed company, such as JPMorgen and Witan trust, which aims to concentrate large number of investors and fund to invest and operate in different assets under a single investment (Guy, 1978: p. 443). Hence, according to Guy (1978: p. 446), a great advantage of investment trust is diversified risk and avoid continuing loses in a single investment. In addition, investing in a well performance trust is a perfect choice to gain a stable return and enhance efficiency in the use of funds. However, it is a key important way for in- 
vestors to measure an investment trust or portfolio performance.

\subsection{Explanation of Portfolio Performance Measures}

The main aim to measure portfolio performance is to forecast the future trend and process in order to invest and gain return. Therefore, the primary objective is to exploit a series of ratios or models, such as Sharpe ratio and Capital Asset Pricing Model (CAPM), to identify over-valued or under-value stock based on historical data (Fletcher \& Forbes, 2002: p. 476). However, it is very difficult for a single measure or stock to analyze and present an accuracy trend. It means that combining various ratios and comparing with other stocks and market index are important.

\section{Analysis}

\subsection{Average Daily Return}

From Figure 1, all of these three trusts have a positive average daily return, as time goes on, trend is going to increase firstly and decrease later. From the perspective of risk, JPMorgan performs a smaller fluctuation and more smoothly, which means that risks have less impact on JPMorgan. Monks and Witan have a bigger and similar fluctuation (Fama \& French, 2003). From the perspective of return, Monks performs best overall, Witan is the worst. If only absolute returns are considered, Monks is the best choice for this wealthy investor ( $\mathrm{Li} \& \mathrm{Wu}$, 2006: p. 2698). However, Monks also has a bigger fluctuation, which means that investors have to take more investment risks. Because different trusts have different risk fluctuation levels, it is also necessary and important for investor to consider risk tolerance excepted return. Hence, for excluding the impact of different risks on investment, the Sharpe ratio is useful and helpful to measure and analyze the return of these three companies under unit risk.

\subsection{Sharpe Ratio}

Sharpe ratio is a measure of excess return against risk-free rate, which is used to present the return of a portfolio for investors (Israelsen, 2005: p. 423). Hence, the higher Sharpe ratio a portfolio shows, the better performance it has. In

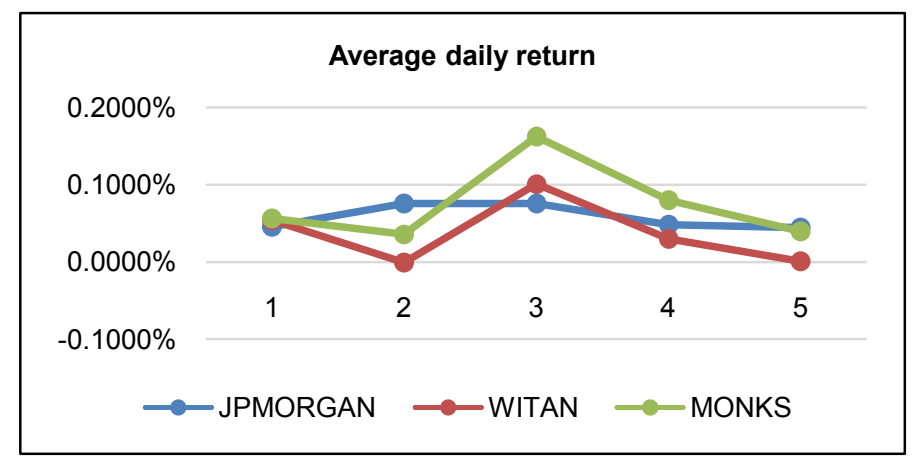

Figure 1. Average daily return. 
addition, according to formula, it is obvious that the excess return what Sharpe ratio shows is under total risk or per unit risk.

According to Figure 2, the Sharpe ratios of all three trusts are positive during these five years. In addition, as time goes on, all of them show a trend of rising in third year and then declining later. The difference is in year 2, the Sharpe ratio of JPMorgan also rises, however, Monks and Witan has a trend to fail at the same time. From the index of their Sharpe ratio, all of them are similar in first year and have different trend after that, which means that excess return under total risk is going to be different. Among them, the movements of Monks and Wi$\tan$ are close and the fluctuations are obvious. On the contrary, JPMorgan has a more gentle trend. Furthermore, compared with Witan, Monks always has a higher index.

Because Sharpe ratio measures the excess return under per unit risk, all of them can outperform the $1 \%$ risk-free returns, and their excess return under equal risk go up firstly and down later. In addition, Witan is almost lowest in these five years, Monks outperforms JPMorgan in the medium term and underperforms in the end. It means that Monks has greater possibility to get unexpected return under same or equal total risk and JPMorgan performances more stable and steady (Kalra, 2001: p. 75). However, each trust has different risk fluctuations. Risk tolerance and appetite also should be considered except return. Hence, according to Pak \& Mahmood (2015: p. 376), for different investment styles, the former is a better choice for the active or growth investor, and for conservative and mature investor, the latter is more suitable. However, compared with these two trusts, Witan not only performs the worst but also has high volatility. This means it is not the best choice anyway for investor.

\subsection{Treynor Ratio}

Treynor ratio is also a measure of excess return against risk-free rate. Scholz \& Wilkens (2005: p. 18) state that the difference compared with Sharpe ratio is that Treynor ratio is divided by the sensitivity of the portfolio to changes in the overall market (Beta, $\beta$ ), which means Treynor ratio considers the excess return is under systematic risk and is for well-diversified portfolios.

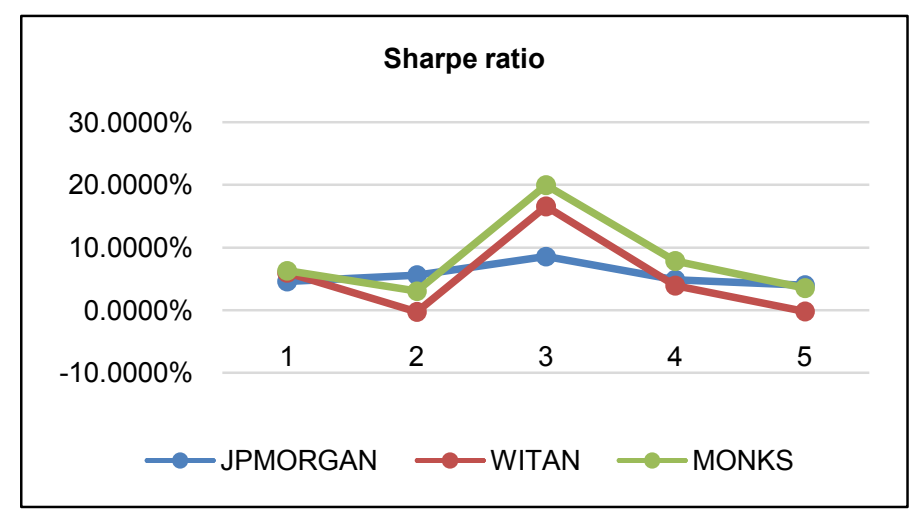

Figure 2. Sharpe ratio. 
As can be seen in the Figure 3, the Treynor ratio of JPMorgan increases firstly and decreases later but the fluctuations are gentle, but Monks and Witan have obvious undulations where the former is higher. In addition, corresponding to the figure of Sharpe ratio, Monks and Witan also have a similar trend in Treynor ratio, which is different with JPMorgan. Moreover, compared with the Average daily return, after excluding system risks, the trend of these three trusts have not changed significantly. This means that unsystematic risk has little effect on the movement of these three companies (Scholz \& Wilkens, 2005: p. 10). Therefore, when comparing the three companies excluding the system risk, it can be seen that in the individual differences of the companies themselves, Witan performed the worst, JPMorgan was quite satisfactory, and Monks performed the best. Hence, for active and positive investors, Monks can help them grasp the individual premium better, which is same conclusion as Sharpe ratio.

\subsection{Information Ratio}

Information ratio is usually used to measure and indicate the residual return of the portfolio relative to its benchmark divided by tracking error which is the standard deviation of the difference between portfolio return and benchmark return (Israelsen, 2005: p. 423). In addition, the benchmark has better reflects on the market returns at same time than the risk-free returns. It means that information ratio is more useful and meaningful than Sharper ratio for investors. Compared with Treynor ratio, the information ratio mainly measures excess return under unsystematic risks.

It can be seen from Figure 4, all of three trusts almost have positive information ratios. By comparation, Monks has bigger undulation than Witan, JPMorgan is more gentle. These show that all of these three trusts can outperform the market during the same period, however, as time goes on, their excess returns under the same unsystematic risks are uncertain (Schneider, 2010: p. 26). Besides that, compared with Sharpe and Treynor ratio, the trend of Witan and Monks is also similar, which is different with JPMorgan. Hence, the influences of unsystem fluctuations and system fluctuations on JPMorgan are different, but they are bisically same for Monks and Witan. Furthermore, compared with Average daily return, after excluding unsystematic risk, the information ratio of JPMorgan has

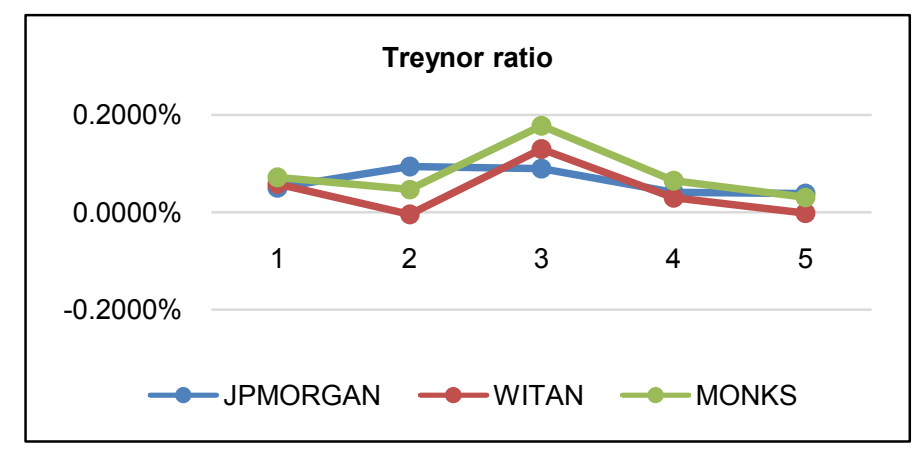

Figure 3. Treynor ratio. 


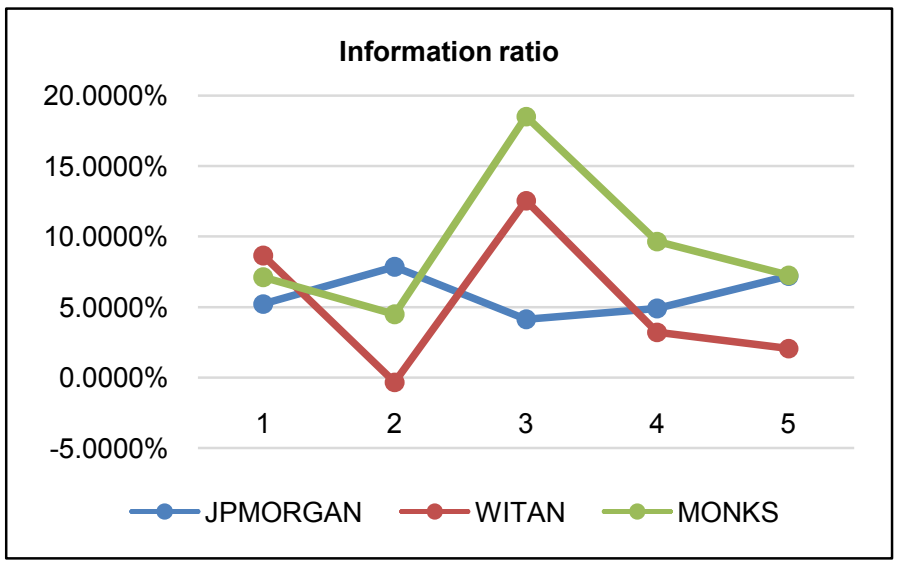

Figure 4. Information ratio.

Table 1. Sharpe ratio, Treynor ratio, and information ratio over the last five years.

\begin{tabular}{cccc}
\hline RATIO & JPMorgan & Witan & Monks \\
\hline SHARPE & 0.051354 & 0.039908 & 0.074991 \\
TREYNOR & 0.000604 & 0.000398 & 0.00084 \\
INFORMATION & 0.055568 & 0.046233 & 0.090709 \\
\hline
\end{tabular}

a bigger change. This means that unsystematic risk has a greater impact on JPMorgan than Witan and Monks. Therefore, under the influence of market changes, Witan performed the worstand Monks performed the best, which is same as the previously analyzed conclusions (Zainuddin et al., 2011: p. 8879). Hence, for passive investors, Monks is also better choice.

\section{Conclusion}

According to Table 1, whether Sharpe ratio, Treynor ratio, or information ratio, Monks has the highest index and better performance. This means that not only considering total risk or per unit risk but also focusing on systemic or unsystematic risk, Monks has a better performance in these five years. Besides that, whether to use risk-free returns or FTSE all share returns as a benchmark comparison, Monks is also a better choice for this wealthy investor.

\section{Conflicts of Interest}

The author declares no conflicts of interest regarding the publication of this paper.

\section{References}

Fama, E., \& French, K. (2003). The Capital Asset Pricing Model: Theory and Evidence. Journal of Economic Perspectives, 18, 25-46. https://doi.org/10.1257/0895330042162430

Fletcher, J., \& Forbes, D. (2002). An Exploration of the Persistence of UK Unit Trust Per- 
formance. Journal of Empirical Finance, 9, 475-493.

https://doi.org/10.1016/S0927-5398(02)00006-3

Guy, J. (1978). The Performance of the British Investment Trust Industry. The Journal of Finance, 33, 443-455. https://doi.org/10.1111/j.1540-6261.1978.tb04860.x

Israelsen, C. (2005). A Refinement to the Sharpe Ratio and Information Ratio. Journal of Asset Management, 5, 423-427. https://doi.org/10.1057/palgrave.jam.2240158

Kalra, R. (2001). Adjusting for Risk: An Improved Sharpe Ratio. CFA Digest, 31, 74-76.

Li, J., \& Wu, C. (2006). Daily Return Volatility, Bid-Ask Spreads, and Information Flow: Analyzing the Information Content of Volume. The Journal of Business, 79, 2697-2739. https://doi.org/10.1086/505249

Pak, O., \& Mahmood, M. (2015). Impact of Personality on Risk Tolerance and Investment Decisions. International Journal of Commerce and Management, 25, 370-384. https://doi.org/10.1108/IJCoMA-01-2013-0002

Schneider, C. (2010). How Useful Is the Information Ratio to Evaluate the Performance of Portfolio Managers? (pp. 12-33). Hamburg: Diplomica Verlag.

Scholz, H., \& Wilkens, M. (2005). Investor-Specific Performance Measurement: A Justification of Sharpe Ratio and Treynor Ratio. International Journal of Finance, 17, 1-20.

Zainuddin, Z., Rosmimah, M., \& Norzaidi, M. (2011). The Influence of Market Orientation on the Commitment, Trust and Relational Norms in the Education Context. African Journal of Business Management, 5, 8875-8890.

https://doi.org/10.5897/AJBM11.291 